Миклина Любовь Игоревна

старший преподаватель кафедры "Социология и культурология" Московского государственного технического университета им. Н.Э. Баумана

\section{СОЦИАЛЬНО-ФИЛОСОФСКИЕ ОСНОВЫ ИССЛЕДОВАНИЯ КОЛЛЕКТИВНОЙ ПАМЯТИ}

Аннотация:

Статья посвящена теоретическим и методологическим основам исследования социальной памяти. Представлен обзор теорий коллективной памяти в философии, социальной философии и психологии. Om истоков проблемы в работах философов Античности произведен переход к описанию философского, психологического и социологического подходов к изучению коллективной памяти. Рассматривается возможный вклад философских и социально-философских концепций в становление теории коллективной памяти. Проводится обзор философской и психологической литературы по заявленной тематике, анализируется ее последующее влияние на становление социологических концепций. Подчеркивается решающая роль памяти в человеческой истории с точки зрения стабильности и интеграции общества.

Ключевые слова:

память, коллективная память, социальная память, философские основы, психологический подход, социологический подход, теория памяти, коллективное бессознательное.
Miklina Lyubov Igorevna

Senior Lecturer, Social Science and Cultural Studies Department, Bauman Moscow State Technical University

\section{THE SOCIAL AND PHILOSOPHICAL FOUNDATIONS OF THE COLLECTIVE MEMORY STUDIES}

Summary:

The article deals with the theoretical and methodological foundations of social memory studies. The paper provides an overview of collective memory theories in philosophy, social philosophy and psychology. On the one hand, the research investigates the origins of the problem in the antique philosophical works. On the other hand, it describes the philosophical, psychological and sociological approaches to the study of collective memory. The paper discusses how philosophy and social philosophy might contribute meaningfully to the discussions of collective memory. It reviews the philosophical and psychological literature on the theory of memory and connects these approaches to the sociological concepts. The author outlines that memory plays a crucial role in human history providing social integration and stability.

Keywords: memory, collective memory, social memory, philosophical foundations, psychological approach, sociological approach, memory studies, collective unconscious.

В современной социологической мысли значительное место занимает теория коллективной памяти. Социальные проблемы и угрозы, вызванные глобализацией и переходом к информационному обществу, придают исследованиям, посвященным данной теме, особую актуальность. Социальная память, коллективное бессознательное, лежащее в основе культуры народа, его ценностей, обычаев и традиций, выступает механизмом интеграции и стабилизации общества в контексте социальных перемен. Значимость данного феномена привлекает внимание представителей зарубежной и российской науки. Изучение социальной памяти становится одним из приоритетных направлений социальной и фрилософской мысли.

Сложность рассматриваемой проблематики состоит в том, что само понятие «коллективная память» является относительно новым для научного дискурса и исследуется на стыке нескольких дисциплин. Социальная память выступает предметом изучения фрилософии, социологии, психологии, социальной психологии, антропологии, истории, этнографии, этнологии и других наук. Но даже в рамках отдельно взятой дисциплины не существует единой методологии изучения данного феномена: мы имеем дело со множеством конкурирующих между собой и дополняющих друг друга подходов. В настоящей статье рассмотрены социально-философрские основы теории памяти, положившие начало актуальному для современной науки направлению memory studies.

Философская традиция изучения памяти заложена еще во времена Античности. В первую очередь здесь стоит упомянуть Платона, Аристотеля и Плотина [1]. Внимание мыслителей было сосредоточено на работе индивидуального сознания, поднимались вопросы, касающиеся природы воспоминаний. Несмотря на отличия отдельных теорий, память рассматривалась в неразрывной связи с процессом мышления и познания. Так, одним из ключевых положений гносеологии Платона является отождествление знания и припоминания: «Знание на самом деле не что иное, как припоминание: то, что мы теперь припоминаем, мы должны были знать в прошлом» [2]. Память, согласно Платону, есть способность души, которая заключается в воспроизведении («припоминании») истинных сущностей, или «идей», вещей. В процессе обучения и познания душа вспоминает то, что она уже знала, когда существовала в царстве идей. В диалоге «Теэтет» 
память сравнивается с отпечатком на восковой дощечке: «То, что застывает в этом воске, мы помним и знаем, пока сохраняется изображение этого, когда же оно стирается или нет уже места для новых отпечатков, тогда мы забываем и больше уже не знаем» [3]. Метафора восковой дощечки позволяет раскрыть роль памяти как основы процесса познания, имеющего идеальную природу, независимую от чувственного опыта. Однако речь здесь идет прежде всего об индивидуальном сознании и автобиографической памяти. Тем не менее базовые принципы и положения данных концепций применимы и к анализу феноменов коллективного сознания. Таким образом, уже в рассуждениях древних фрилософов можно увидеть те идеи, которые послужили отправными точками в научном исследовании памяти.

В Средние века рассматриваемая проблематика получает новую окраску, вопрос о природе памяти решается с позиции религиозной философии. Августин Блаженный выделял три атрибута или способности души: разум, волю и память [4]. При этом память присуща лишь человеку и является самой значительной частью души, в которой заключена идея Бога. В своей «Исповеди» философ и епископ буквально восхваляет возможности памяти: «Велика она, эта сила памяти, Господи, слишком велика! Это святилище величины беспредельной» [5]. Так, память, понимаемая в Античности как свойство разума, в средневековой философии становится способностью души и наделяется божественной сущностью. При этом сохраняется преемственность с образом платоновской восковой дощечки: «Люди извлекают из памяти не сами события - они прошли, - а слова, подсказанные образами их: прошлые события, затронув наши чувства, запечатлели в душе словно следы свои» [6].

Согласно Августину, в памяти содержатся образы чувственных восприятий, «сведения, полученные при изучении свободных наук», соотношения величин, законы и «душевные состояния». Раскрывая таким образом структуру памяти, средневековый философр отрицает ее трансцендентную природу и связывает с совокупностью чувственного опыта, накопленного в течение жизни. Августин Блаженный отводит особое место проблеме взаимосвязи памяти и времени. Если время линейно и движется из прошлого в будущее, то направленность памяти прямо противоположна, она дает возможность повернуть время вспять. Подчеркивая значение человеческой памяти, средневековая философрия не строит систематизированной теории, механизмы функционирования сознания остаются вне поля зрения науки. Однако, в отличие от античных мыслителей, Августин понимает память как совокупность жизненного опыта индивида, что имеет решающее значение при построении теории коллективной памяти как хранилища человеческой культуры.

Основа анализа френомена памяти с позиции научного знания была заложена фрилософами Нового времени Т. Гоббсом и Дж. Локком [7]. Развитие естественных наук, повсеместное внедрение экспериментального метода рождают эмпиризм в социальной мысли. В этот период проблематика памяти окончательно закрепляется в гносеологии и связывается с чувственным опытом. Исходя из принципа эмпиризма, Джон Локк утверждает, что в памяти нет врожденных идей - только воспринятые ранее, осознанные и ставшие воспоминаниями. Таким образом, память есть «кладовая наших идей», а воспоминание - не что иное, как «восстановление восприятий» [8]. Сведение функции памяти к хранению ощущений не снижает ее значимости: «Она настолько важна, что там, где ее нет, все остальные наши способности... бесполезны» [9]. Именно память позволяет человеку выйти за пределы непосредственно воспринимаемого. Можно провести аналогию с коллективными представлениями: они расширяют горизонты индивидуального сознания, включая в него опыт группы. Непрерывность воспоминаний, согласно Локку, создает и поддерживает идентичность, как личную, так и коллективную. Следовательно, память играет ключевую роль в формировании самосознания индивида и группы. Английский эмпиризм продолжает традицию, идущую от А. Августина, в которой память понимается как продукт жизненного опыта человека. Учение о памяти лишается иррационального элемента, как это было в Средние века, но не поднимается на уровень социального феномена.

Проблема памяти и воспоминания нашла свое отражение в немецкой классической философии [10]. Здесь она рассматривается в русле идеализма и априоризма: память - это не комплекс ощущений, а этап в развитии мысли. Если у А. Августина память составляет свойство человеческой души, то в диалектике Г.В.Ф. Гегеля она предстает как этап саморазвития духа. Ступеней возвышения «духа как такового» три: чувство, представление и мышление [11; 12, с. 181195]. Память участвует в формировании представления, отделяясь таким образом от чувственного опыта, и включает в себя воспоминание, воображение и собственно память.

Ценным является проведенное Г.В.Ф. Гегелем различие между продуктивной и репродуктивной памятью: продуктивная составляющая производит соединение созерцания с представлением, репродуктивная состоит в запоминании знаков и удержании их образных рядов. Понятие продуктивной памяти содержит в себе указание на ее активность, а также тот факт, что уже существующие представления согласуются с текущими. В философрии XVII-XIX BB. теория памяти 
получает научное обоснование, внимание ученых сосредоточивается не на метафизической или иррациональной природе данного феномена, а на его роли и месте в процессе человеческого познания и мышления. В этот период закладываются основы того теоретико-методологического подхода, который в дальнейшем будет реализован в психологии и социологии.

По мере развития философской мысли представление о памяти как элементе социального бытия развивалось в рамках нескольких дисциплинарных направлений, что в последующем послужило причиной формирования множества подходов к ее изучению и обусловило сложный характер ее исследования. Помимо философии, память становится предметом изучения психологии, социальной психологии, истории, культурологии, семиотики, антропологии и других наук. В течение длительного периода времени концепт памяти разрабатывался в рамках психологической науки, откуда позже был заимствован другими отраслями знания, в том числе социологией. В русле данного направления в первую очередь рассматривались проблемы индивидуальной или автобиографической памяти.

На стыке психологии и философии проблема памяти разрабатывалась в трудах основоположника интуитивизма А. Бергсона. Ученый различал два типа памяти: память тела («памятьпривычку») - «совокупность рационально устроенных механизмов» и память духа (спонтанную, настоящую память) [13]. Прошлое, по Бергсону, может накапливаться в виде типичных двигательных механизмов («привычек мозга») и индивидуальных образов-воспоминаний. Первый род памяти относится к телесной составляющей и располагается в настоящем. Второй «сохраняет прошедшее в силу естественной необходимости» в виде образов и делает возможным интеллектуальное узнавание, обращенное к прошлому. Первая память повторяет, вторая - воображает. Та часть теории А. Бергсона, в которой описывается «память-привычка», может быть использована только при исследовании индивидуального сознания. В противоположность этому положения о спонтанной или настоящей памяти составляют основу анализа феноменов массового сознания, связанных с коллективными воспоминаниями.

Переход от психологии индивида к психологии социальных групп и масс был осуществлен в русле социально-психологического подхода, большую роль в развитии которого сыграла концепция «коллективного бессознательного» К.Г. Юнга. Согласно Юнгу, у каждого человека, помимо личных воспоминаний, существуют «унаследованные возможности человеческих представлений» или безличное бессознательное [14, с. 79]. Коллективное (трансличное) бессознательное коренится в опыте всего человечества и находит свое выражение в архетипах. Архетипы, или «изначальные образы» - это наиболее древние и универсальные «мыслеформы» человечества, такие как самость, персона, тень, анима, анимус и др. [15, с. 81]. Теория коллективного бессознательного послужила мостиком, связывающим психологические концепции памяти, в центре которых - работа индивидуального сознания, и зарождавшиеся представления о социальной природе воспоминаний. Так на стыке философии и социальной психологии сформировались предпосылки, позволившие перевести анализ феномена памяти с индивидуального на социальный уровень.

В первой половине XX в. границы memory studies расширяются. Если раньше теория памяти была прерогативой психологических исследований, то на этом этапе социология в лице дюркгеймовской школы заимствует понятие памяти из психологии и дает ему собственную интерпретацию. На пересечении двух областей социогуманитарного знания оформляется теория коллективной памяти. Именно в социологии память получает статус социального феномена, имеющего объективный и надындивидуальный характер.

В последние десятилетия тема коллективной памяти становится все более актуальной как в социологии, так и в смежных областях научного знания. Одновременно развивается несколько теоретико-методологических подходов в изучении этого феномена. Проблематика коллективной памяти разрабатывается в контексте психологических, социально-психологических, исторических, культурологических и социологических исследований. В рамках социологической науки полипарадигмальность находит свое отражение в сосуществовании нескольких групп теорий социальной памяти. Все это создает значительные трудности при выделении границ феномена и понимании его сущности - трудности, которые развивающейся науке еще предстоит преодолеть.

\section{Ссылки:}

1. См.: Аристотель. О памяти и припоминании [Электронный ресурc]. URL: http://www.nsu.ru/classics/bibliotheca/Aristotlede\%20memoria.pdf (дата обращения: 02.06.2017) ; Платон. Теэтет [Электронный ресурc]. URL: http://grani.roerich.com/plato/txt/theaetetus.htm (дата обращения: 02.06.2017) ; Его же. Федон [Электронный ресурc]. URL: http://psylib.ukrweb.net/books/plato01/19fedon.htm (дата обращения: 02.06.2017) ; Плотин. Об ощущении и памяти [Электронный ресурc]. URL: http://ec-dejavu.ru/m/Memory_Greek.html\#plotinus (дата обращения: 02.06.2017).

2. Платон. Федон.

3. Платон. Теэтет. 
4. Августин А. Исповедь [Электронный ресурc]. URL: http://psylib.ukrweb.net/books/avgus01/index.htm (дата обращения: 04.06.2017).

5. Там же.

6. Там же.

7. См.: Гоббс Т. Левиафан [Электронный ресурc]. URL: https://www.litmir.me/br/?b=55452 (дата обращения: 04.06.2017) ; Локк Дж. Опыт о человеческом разумении [Электронный ресурc]. URL: http://lms.hse.ru/content/lessons $/ 1004 / \% D 0 \% 9 B \% D 0 \% B 8 \% D 1 \% 82 \% D 0 \% B 5 \% D 1 \% 80 \% D 0 \% B 0 \% D 1 \% 82 \% D 1 \% 83 \% D 1 \% 80 \% D 0 \% B 0 \% 20 \% D 0 \% B 8 \%$ D1\%81\%D1\%82\%D0\%BE\%D1\%80\%20\%D0\%BF\%D1\%81\%D0\%B8\%D1\%85/locke_essay_concerning_human_understanding.pdf (дата обращения: 04.06.2017).

8. Локк Дж. Указ. соч.

9. Там же.

10. См.: Гегель Г.В.Ф. Введение в философию. Философрская пропедевтика / пер. с нем. С.Ф. Васильева. М., 2016 ; Дильтей В. Наброски к критике исторического разума // Вопросы философиии. 1988. № 4. С. 135-152 ; Кант И. Антропология с прагматической точки зрения / пер. с нем. Н.М. Соколова. Изд. 3-е. М., 2012.

11. Блонский П.П. Память и мышление [Электронный ресурс]. М. ; Л., 1935. 213 c. URL: http://elib.gnpbu.ru/textpage/download/html/\%3Fbookhl\%3D\%26book\%3Dblonsky_pamyat-myshlenie_1935 (дата обращения: 04.06.2017).

12. Гегель Г.В.Ф. Указ. соч. С. 181-195.

13. Бергсон A. Материя и память [Электронный pecypc]. URL: http://www.filosof.historic.ru/books/item/f00/s00/z0000978/st000.shtml (дата обращения: 04.06.2017) ; Perri T. Bergson's Philosophy of Memory // Philosophy Compass. 2014. Vol. 9, no. 12. P. 837-847.

14. Юнг К.Г. Очерки по психологии бессознательного / пер. с англ. В.В. Зеленского. М., 2010.

15. Там же. С. 81.

\section{References:}

Aristotle, 2017, On memory and reminiscence, viewed 02 June 2017, <http://www.nsu.ru/classics/bibliotheca/Aristotlede\%20memoria.pdf>, (in Russian).

Augustine, A 2017, Confession, viewed 04 June 2017, <http://psylib.ukrweb.net/books/avgus01/index.htm>, (in Russian).

Bergson, A 2017, Matter and memory, viewed 04 June 2017, <http://www.filosof.historic.ru/books/item/f00/s00/z0000978/st000.shtml>, (in Russian).

Blonsky, PP 1935, Memory and thinking, Moscow, Leningrad, 213 p., viewed 04 June 2017, <http://elib.gnpbu.ru/textpage/download/html/\%3Fbookhl\%3D\%26book\%3Dblonsky_pamyat-myshlenie_1935>, (in Russian).

Dilthey, V 1988, 'Sketches for a critique of historical reason', Voprosy filosofii, no. 4, pp. 135-152, (in Russian).

Hegel, GWF \& Vasilyev, SF (transl.), Introduction to philosophy. Philosophical propaedeutic, Moscow, (in Russian).

Hobbes, T 2017, Leviathan, viewed 04 June 2017, <https://www.litmir.me/br/?b=55452>, (in Russian).

Jung, CG \& Zelensky, VV (ed.) 2010, On the psychology of the unconscious, Moscow, (in Russian).

Kant, I \& Sokolov, NM (transl.) 2012, Anthropology from a pragmatic point of view, $3^{\text {rd }}$ ed., Moscow, (in Russian).

Locke, J 2017, An essay concerning human understanding, viewed 04 June 2017, <http://lms.hse.ru/content/lessons/1004/\%D0\%9B\%D0\%B8\%D1\%82\%D0\%B5\%D1\%80\%D0\%B0\%D1\%82\%D1\%83\%D1\%80\%D0\%B0\%20\%D0\%B8\%D1\% $81 \% \mathrm{D} 1 \% 82 \% \mathrm{D} 0 \% \mathrm{BE} \% \mathrm{D} 1 \% 80 \% 20 \% \mathrm{D} 0 \% \mathrm{BF} \% \mathrm{D} 1 \% 81 \% \mathrm{D} 0 \% \mathrm{~B} 8 \% \mathrm{D} 1 \% 85 /$ locke_essay_concerning_human_understanding.pdf>, (in Russian).

Perri, T 2014, 'Bergson's Philosophy of Memory', Philosophy Compass, vol. 9, no. 12, pp. 837-847, https://doi.org/10.1111/phc3.12179.

Plato, 2017a, Phaedo, viewed 02 June 2017, <http://psylib.ukrweb.net/books/plato01/19fedon.htm>, (in Russian).

Plato, 2017b, Theaetetus, viewed 02 June 2017, <http://grani.roerich.com/plato/txt/theaetetus.htm>, (in Russian).

Plotinus, 2017, On sensation and memory, viewed 02 June 2017, <http://ec-dejavu.ru/m/Memory Greek.html\#plotinus>, (in Russian). 